\title{
INTERPLANT COMPETITION AS A BIASING FACTOR IN EVALUATING PRE-TREATMENT EFFECTS IN CUCUMBER
}

\author{
A.H.C.M. SCHAPENDONK ${ }^{1}$ and C.J.T. SPITTERS ${ }^{2}$ \\ ${ }^{1}$ Centre for Agrobiological Research, P.O. Box 14, 6700 AA Wageningen \\ (The Netherlands) \\ ${ }^{2}$ Department of Theoretical Production Ecology, Agricultural University, \\ P.O. Box 430, $6700 \mathrm{AK}$ Wageningen (The Netherlands)
}

(Accepted for publication 25 April 1984)

\begin{abstract}
Schapendonk, A.H.C.M. and Spitters, C.J.T., 1984. Interplant competition as a biasing factor in evaluating pre-treatment effects in cucumber. Scientia Hortic., 24: 115-122.

Evaluation of effects of different environmental conditions on plant growth may be seriously biased by interplant competition if treatment plots are not well-bordered. This is shown with an experiment where low- and high-light pre-treated cucumber plants were grown for 6 weeks in a mixture, either in a shaded or in an unshaded glasshouse compartment. In these mixed stands, the high-light pre-treated plants, compared to the low-light pre-treated plants, produced $80 \%$ more leaf area in the shaded compartment and $40 \%$ more leaf area in the unshaded compartment. However, when both pre-treatments were not mixed but grown separately, as in grower's practice, the calculated advantage of high-light pre-treatment with respect to leaf area development appeared to be only $15 \%$ (shaded) and $5 \%$ (unshaded).

With an explanatory growth model, it is shown that in a mixture, the absolute difference between the components increases in time due to interplant competition, but that the percentage difference remains constant in time and therefore corresponds with the difference in initial status. Deviations from constancy of percentage difference occur in favour of types with a greater plant height or producing a greater leaf area per unit biomass than their competitors.
\end{abstract}

Keywords: competition; Cucumis sativus; plot technique; pre-treatment; simulation model.

\section{INTRODUCTION}

In glasshouses and climate rooms, the available area often imposes a restriction on the size of experiments. The treatment plots, therefore, tend to be small. The trend towards small plots is reinforced by the principle that an increased number of replicates improves statistical accuracy, but necessarily with a concomitant decrease of plot size when total area is fixed.

However, the drawback of small plots is that adjacent plots may interfere 
substantially with each other. Treatments which increase the competitive ability of the plants in one plot above that of neighbouring plots will give rise to a higher yield in small plots than in large, well-bordered plots. The opposite is true for treatments which reduce the competitive ability of the plants.

Competition between adjacent plots has frequently been demonstrated in arable crops, especially cereals, and authors have pointed to the bias in evaluation of treatment effects that can arise from use of poorly-bordered plots (review in Spitters, 1979). Use of small and unbordered plots is more widespread in glasshouses and climate rooms, but we are not aware of a critical analysis of the competitional bias in horticultural experiments. This paper reports on a study of this bias in a glasshouse crop.

In most of the agricultural studies on the disturbance that arises from interplot competition, only final yields are observed. As far as a further analysis of differences in competitive ability is concerned, this is done in a descriptive way by correlating yield in mixture with morphological traits. In a recent paper (Spitters, 1984), a simple explanatory model was presented in order to arrive at causal backgrounds of differences in competitive ability between treatments. The present study considers in more detail the causal, physiological aspects of the competitional bias. A competitive situation was created by growing low-light pre-treated and high-light pre-treated cucumber plants side by side in a mixture. A simulation model for crop growth is used to show how the effects of competition develop in the course of time, and which plant characteristics lead to a high competitive ability.

\section{MATERIALS AND METHODS}

Cucumber plants, Cucumis sativus L., were grown for 22 days on nutrient solution in a climate room at $25^{\circ} \mathrm{C}$. One group of plants received photosynthetically active radiation (PAR) from high-pressure mercury lamps with an intensity of $30 \mathrm{~W} \mathrm{~m}^{-2}\left(130 \mathrm{~J} \mathrm{~cm}^{-2}\right.$ day $\left.^{-1}\right)$, while the other group received $85 \mathrm{~W} \mathrm{~m}^{-2}\left(367 \mathrm{~J} \mathrm{~cm}^{-2}\right.$ day $\left.^{-1}\right)$. The photoperiod was $12 \mathrm{~h}$.

After the pre-treatment period, the plants were transplanted on 16 March into two glasshouse compartments. In one compartment the plants were shaded with cheese-cloth that transmitted $45 \%$ of the light. Thus, four treatments were established: $\mathrm{L} \rightarrow \mathrm{L}$ (from a low light intensity in the climate room to a shaded compartment); $\mathrm{H} \rightarrow \mathrm{L}$ (high light intensity to shade); $\mathrm{L} \rightarrow \mathrm{H}$ (low light intensity to no shade) $\mathrm{H} \rightarrow \mathrm{H}$ (high light intensity to no shade). Averaged over the growing period, incident PAR at the top of the canopy was $255 \mathrm{~J} \mathrm{~cm}^{-2} \mathrm{day}^{-1}$ in the unshaded, and $115 \mathrm{~J} \mathrm{~cm}^{-2} \mathrm{day}^{-1}$ in the shaded, situation. In each compartment, plants of both pre-treatments were mixed and compared in 8 replicates. Planting density was 2 plants $\mathrm{m}^{-2}$.

Irradiance inside the glasshouse above the cheese-cloth was measured with a Kipp thermopile. PAR was estimated to be $60 \%$ of diffuse, and $50 \%$ 
of direct, shortwave radiation. The temperature set-point in the compartments was $22^{\circ} \mathrm{C}$ for the light period and $20^{\circ} \mathrm{C}$ for the dark period.

Expansion of leaf area $(L)$ was estimated from periodical measurements of the length and width of the leaves using the third-degree polynomial

$L=-0.626+1.076 P-0.00929 P^{2}-0.00046 P^{3}$

where $P=$ length $X$ width with both $L$ and $P$ in $\mathrm{dm}^{2}$ (Schapendonk and Brouwer, 1984). Plant biomass was proportional to leaf area until the onset of fruiting, between Days 23 and 30 depending on the treatment. In order to continue this proportionality in the figures, fruit weight was converted to an equivalent leaf area by multiplication by 0.54 , the fraction of the dry weight allocated in the leaves during the vegetative phase, and by the specific leaf area as measured on Day 42. This specific leaf area was $3.85 \mathrm{dm}^{2} \mathrm{~g}^{-1}$ for the unshaded plants and $6.60 \mathrm{dm}^{2} \mathrm{~g}^{-1}$ for the shaded plants. So the trends in biomass can be derived from the figures by multiplying LAI by $48 \mathrm{~g} \mathrm{~m}^{-2}$ for the unshaded, and by $28 \mathrm{~g} \mathrm{~m}^{-2}$ for the shaded, compartment. In the model, the real LAI rather than this equivalent LAI was used to simulate light interception.

\section{RESULTS AND DISCUSSION}

Experimental results. - The high-light pre-treatment resulted in a progressively increasing leaf area advantage over the low-light pre-treated plants, both in the shaded and unshaded compartments (Fig. 1). So at first sight, it might be concluded that a high-light pre-treatment of young plants leads to a progressively increasing benefit.

However, as the plants which received the high-light pre-treatment were grown in a mixture with the low-light plants, the greater growth of the high-light plants will have been realized partly at the expense of their lowlight neighbours. Thus, the effects presented in Fig. 1 will over-estimate the perspectives of high-light pre-treatment for the grower, who will use monocultures of plants all pre-treated in the same way. To clarify the causal backgrounds and the magnitude of the competitional bias, the results will be analysed in terms of an explanatory simulation model, and expected growth of each of the pre-treatments in monoculture will be derived.

A simulation model for growth in a mixture and in monoculture. - Total crop growth was simulated with a modified version of the model of Acock et al. (1978) as described by Schapendonk and Gaastra (1984). In the mixture, total growth was allocated every time-step to the two plant groups according to their shares of the total photosynthesizing area.

Gross $\mathrm{CO}_{2}$ assimilation of the total canopy was calculated from the assimilation-light response curve of single leaves, incoming PAR, temperature and simulated total LAI (Acock et al., 1978; Schapendonk and Brouwer, 1984). After subtraction of maintenance respiration, the carbohydrates 


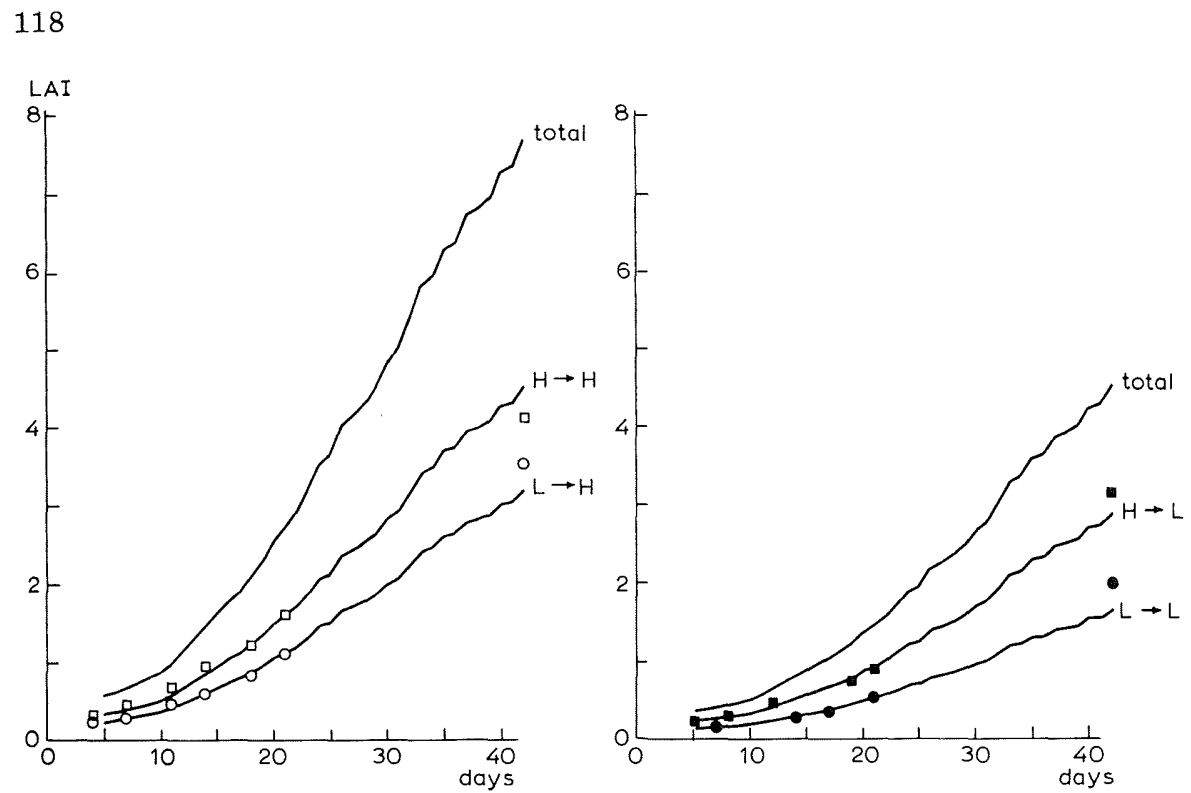

Fig. 1. Simulated time-courses of leaf area index in mixtures where plants pre-treated at high $(\square, \bullet)$ and low $(\circ, \bullet)$ light were grown together either at high light (unshaded, $, 0, \square)$ or at low light (shaded, $\bullet,)^{\prime}$. Circles and squares represent observed data points. Time is in days after transplanting into the glasshouse compartments.

were converted into structural dry matter (Schapendonk and Gaastra, 1984). The total dry matter increment was partitioned between the highand low-light pre-treated plant groups according to their shares of the total LAI (Spitters and Aerts, 1983). Of this dry weight increment, 54\% was allocated to the leaves, which was the percentage found in destructive harvests on Days 21 and 42. Leaf area was calculated by multiplying leaf dry weight by specific leaf area. Specific leaf area is given as a function of temperature and incoming PAR (Schapendonk and Brouwer, 1984). The model was started with the leaf areas observed 5 days after transplanting: $0.13(\mathrm{~L} \rightarrow \mathrm{L}) ; 0.23(\mathrm{H} \rightarrow \mathrm{L}) ; 0.24(\mathrm{~L} \rightarrow \mathrm{H})$; and $0.34(\mathrm{H} \rightarrow \mathrm{H}) \mathrm{dm}^{2}$ plant $^{-1}$.

Time-trend for growth in the mixture. - The curves plotted in Figs. 1 and 2 represent the simulation results. The model gives a close fit to the experimental data.

In the early growth stages, the plants do not shade each other and shading within the plant is also negligible. A certain expansion of the leaf area then leads to a corresponding increase of light interception and $\mathrm{CO}_{2}$ assimilation. This results in exponential growth.

When the canopy is closed, from a total LAI of about 1.5 onwards, most of the incoming light is intercepted and additional leaf area hardly contributes to greater light interception. Daily crop assimilation then moves around a constant value, with the fluctuations being related mainly to those in the daily amount of incident light. This results in an approxi- 


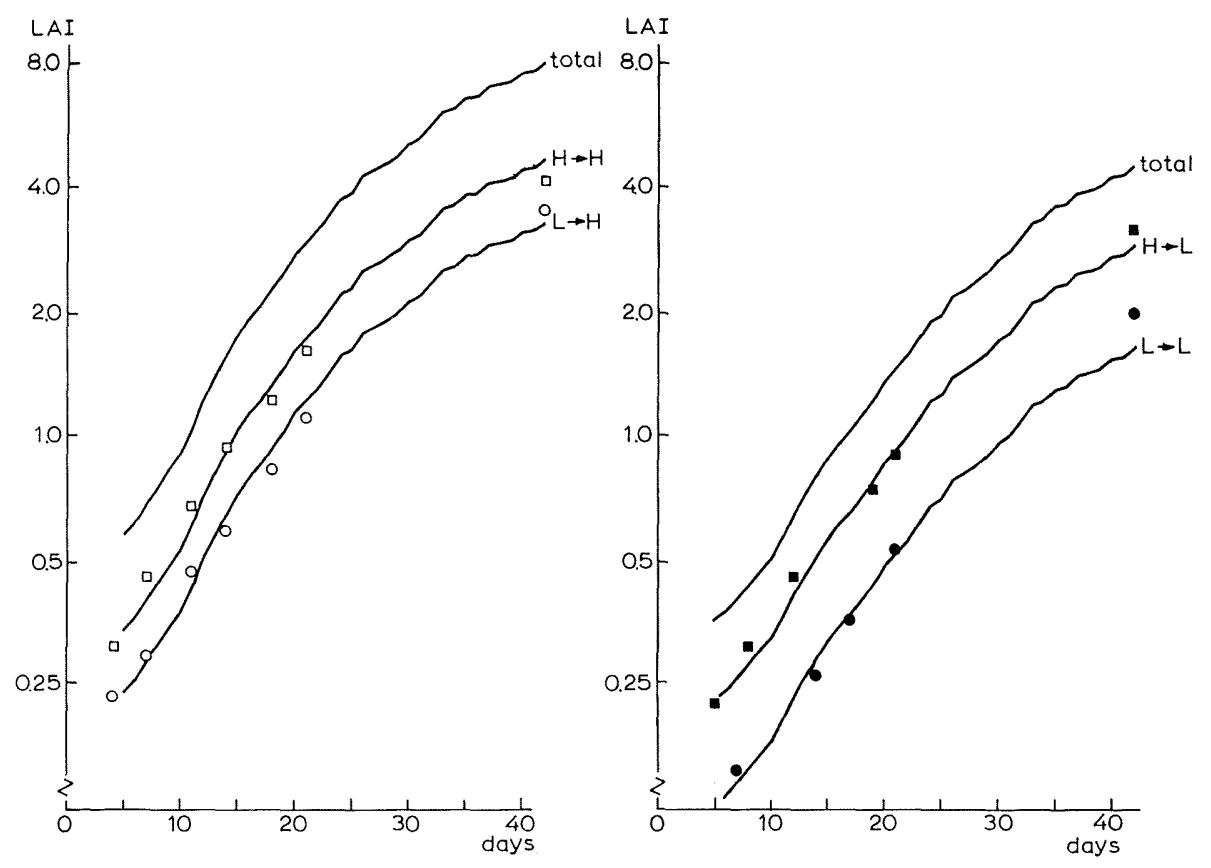

Fig. 2. As Fig. 1, but with leaf area index plotted on a logarithmic scale.

mately constant growth rate and therefore in linear growth of the total stand (Fig. 1).

In a mixture of two components, each acquires that part of the totally absorbed light that corresponds with its share of the total leaf area. As the growth rate is proportional to the light capture, the growth rates of the components correspond with their share of the total leaf area. When both produce the same amount of new leaf area per gram dry weight increment, the share of each component in the total canopy remains constant in time. In the mixture, the components grow linearly, but each at a different rate. Their absolute difference increases progressively (Fig. 1), whereas their relative difference remains constant in time, as is reflected by a constant vertical difference on the logarithmic scale (Fig. 2). Consequently, at any time, their mutual ratio equals their initial ratio. So, the $80 \%$ greater leaf area of the high-light pre-treated plants after transplanting in the shaded compartment resulted in an $80 \%$ greater leaf area at the final harvest.

Competitive status does not necessarily remain constant in time, but may also change during growth. That occurs when one component has placed its leaves partly above that of the other (differences in plant height), when its light-use efficiency is greater, or when it produces a larger leaf area per gram dry weight increment (Spitters and Aerts, 1983; Spitters, 1984). In this experiment, this type of difference was negligible, so that the ratio did not change in time (Fig. 2). 
Time-trend for growth in monoculture. - With the same model, growth curves were also predicted for monocultures, i.e. stands where neighbouring plants are pre-treated in the same way, and these are given in Fig. 3. As in the mixtures, in the early phase the plants do not affect each others' growth and their leaf area increases exponentially. During exponential growth, the growth rate is proportional to the leaf area, so that within each compartment, the high-light pre-treated plants show a somewhat greater growth rate.

When the canopy closes, at a LAI of about 1.5, growth of the pre-treatments in monoculture is going to deviate from their growth in a mixture. In a closed monocrop, each pre-treatment has all of the incoming light at its disposal. Therefore, their growth rates become the same, so that their absolute difference remains constant in time (Fig. 3).

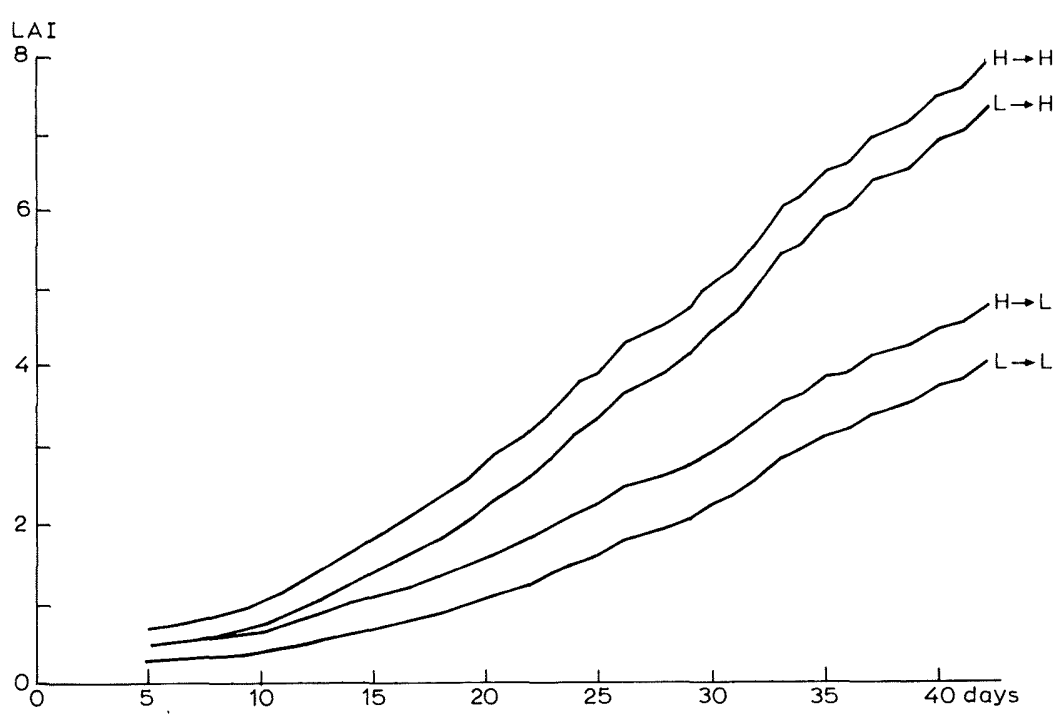

Fig. 3. Simulated time-courses of leaf area index in monocultures of plants pre-treated at low and high light and grown thereafter in a shaded or an unshaded compartment.

The high-light pre-treatment did not give rise to an advantage of $80 \%$ (shaded) or $40 \%$ (unshaded) as in the mixture, but in a much smaller benefit of only $15 \%$ (shaded) or $5 \%$ (unshaded). So the premium of an additional illumination during the first weeks is much smaller in growers' practice, where plants are grown in monoculture, than in experiments as given in Fig. 1, where different pre-treatments are growing in competition.

That competition greatly magnifies the differences between components is a common finding for mixtures of different cultivars (Spitters, 1979, 1984). The magnifying effect also appeared from the experiments where small seeds and large seeds of the same seed sample were sown separately and in mixtures with each other. Plants originating from small seeds gave 
about the same yield in monoculture, but a much lower yield in mixtures, than plants from the large seeds (references in Spitters, 1979, pp. 149 and 177).

The advantage of a larger leaf area of the transplants in monoculture is an earlier canopy closure. With every day that the time of full closure is accelerated, a gain in biomass is achieved equal to the daily growth rate in the linear phase. For example, in the unshaded compartment, canopy closure was reached 2 days earlier by the high-light pre-treated crop (Fig. 3). With a linear growth rate of 0.12 LAI day $^{-1}$, this resulted in a simulated advantage of $0.23 \mathrm{LAI}$ that persists over the entire phase that growth is linear. The relatively greater advantage of the high-light pre-treatment at low light intensity, compared to its advantage at high light, was caused by two phenomena. First, the initial size of the high-light pre-treated plants 5 days after transplanting was $80 \%$ greater in the shaded, and only $40 \%$ greater in the unshaded, compartment, either due to differences in acclimatization or to differences in size of transplants chosen for each compartment. Their relative difference persisted in the mixture and also had some influence on their monoculture performance. The second aspect is that under low light the exponential phase is extended so that the ratio between the linear and exponential phases is smaller at low light. This difference between both environments is reduced as time proceeds.

The advantage of the high-light pre-treatment is a slightly higher biomass in monoculture and an acceleration of flowering. Flowering started 3 days earlier for the high-light pre-treated plants, and it is expected that this morphogenetic trait is little affected by competition.

\section{CONCLUSION}

When the yield of a plot is affected due to competition with adjacent plots, then the comparison of treatments may be seriously disturbed. Such a bias due to interplot competition arises when plots are too small, especially when borders are not discarded. In general, discarding only one row of plants at each side of the plot is sufficient to avoid the effects of interplot competition (Spitters, 1979, pp. 42-46). Models are available to formulate the statistical aspects of the interdependence of interplot competition, number of treatments, number of replicates and plot size (Spitters, 1979, pp. 209-246; 1984).

In this paper, a causal physiological approach was followed in order to demonstrate how competition effects develop and which plant characteristics account for a high competitive ability. It was shown that in competitive situations, those types are favoured which possess a good initial status, produce more leaf area per gram dry matter, or have a greater plant height. 


\section{REFERENCES}

Acock, B., Charles-Edwards, D.A., Fitter, D.J., Hand, D.W., Ludwig, L.J., Warren Wilson, J. and Withers, A.C., 1978. The contribution of leaves from different levels within a tomato crop to canopy net photosynthesis: An experimental examination of two canopy models. J. Exp. Bot., 29: 815-827.

Schapendonk, A.H.C.M. and Brouwer, P., 1984. Fruit growth of cucumber in relation to assimilate supply and sink activity. Scientia Hortic., 23: 21-33.

Schapendonk, A.H.C.M. and Gaastra, P., 1984. A simulation study on $\mathrm{CO}_{2}$ concentration in protected cultivation. Scientia Hortic., $23: 217-229$.

Spitters, C.J.T., 1979. Competition and its consequences for selection in barley breeding. Agric. Res. Rep. (Versl. Landbouwkd. Onderz.), 893: 268 pp.

Spitters, C.J.T., 1984. Effects of intergenotypic competition on selection. Proc, 10th Eucarpia Congress, Pudoc, Wageningen, 1983, pp. 13-27.

Spitters, C.J.T. and Aerts, R., 1983. Simulation of competition for light and water in crop-weed associations. Aspects Appl. Biol., 4: 467-483. 